\title{
Evaluating Group Use of the Information Commons
}

Michael J. Whitchurch

Brigham Young University - Provo, michael_whitchurch@byu.edu

Follow this and additional works at: https://scholarsarchive.byu.edu/facpub

Part of the Library and Information Science Commons

\section{Original Publication Citation}

College and Undergraduate Libraries, vol. 16, no. 1, pp. 71-82

\section{BYU ScholarsArchive Citation}

Whitchurch, Michael J., "Evaluating Group Use of the Information Commons" (2008). Faculty Publications. 1542.

https://scholarsarchive.byu.edu/facpub/1542 


\section{Evaluating Group Use of the Information Commons}

Harold B. Lee Library Information Commons, Fall 2005-Winter 2007 


\section{Evaluating Group Use of the Information Commons}

Abstract: Evaluating the effectiveness of an information commons has been discussed in many venues since the concept was first implemented. The Harold B. Lee Library at Brigham Young University confronted this same struggle. After two years of activity, the information commons had not been assessed to see if the purposes for which it was planned were being fulfilled. This paper describes its first assessment. Measuring the number of groups who used the information commons over the period of two years, the assessment showed that indeed the commons is being used to a great extent for group work, one of the goals set for its creation.

Keywords: Information commons, group study, Brigham Young University, group evaluation

Michael J. Whitchurch, MLIS, is Information Commons Section Head, Harold B. Lee Library, Brigham Young University, Provo, UT 84602 (E-mail:

michael_whitchurch@byu.edu). 


\section{Introduction}

The Harold B. Lee Library (HBLL) at Brigham Young University (BYU) began planning for its information commons in February 2003 and implemented it the following February. The commons currently houses fifty-eight collaborative workstations, sixtythree individual workstations, five public workstations, ten multimedia stations, two group study rooms, and nineteen study tables. It also includes ample open floor space that is often used for group study work.

The development and implementation of the commons occurred for many reasons. The main emphasis was to provide a space for the way in which the new generation of college students study. One of the changes in studying has been the increased use of group projects and group work as a learning tool. Therefore, the commons needed to be a place where students would be comfortable participating in group work as well as giving them access to newer technologies in their pursuit of academic learning and knowledge.

To help ensure the success of the commons, the Information Commons Investigation Team proposed seven components for implementation at BYU. (Whitchurch, Belliston, and Baer 2006, 264) These included: 1. Reference and student workstations; 2. Collaborative learning rooms and areas; 3. Electronic classrooms; 4. Multimedia workstations; 5. Consultation stations; 6 . Writing lab; 7. Lounge area. This article addresses the second of these components: the collaborative nature of the commons.

As with all services, the information commons needs to be evaluated and assessed. Finding ways to effectively evaluate and assess the success of an information commons has been discussed in many venues; however, it is an issue with which the information 
commons community is still struggling. The purpose of beginning this investigative process, resulting in this report, was to discover if students were using the commons for the group work in the library, thereby accomplishing one of the desired goals. This is the first assessment to be implemented in the commons at BYU.

The information commons implementation in the space that was once a quiet general reference area of the library happened over time. Unfortunately, we do not have any statistics regarding the use of the area by groups prior to the implementation of the commons, nor for the first year of operation. Now, however, we have more than two years of data that show that the commons has been, and continues to be, heavily used as an area for group study.

\section{Methodology}

Having no previous data, we supposed that this would be a good baseline of data for future comparisons. We did, however, anticipate that the data would show that the commons is being used to a great extent by students for group work. We also expected to see that the number of groups using the commons during fall semester would be greater than group use during winter semester.

To measure the success of the collaborative nature of the information commons, a simple method to capture this data was devised. The method chosen was a simple count of the number of groups studying in the commons. The count was divided into three group types, whose identification was based on observations by those working in the commons prior to beginning the study. Individuals making these observations while working in the information commons included librarians, library staff and student 
employees. These observations showed that students met as groups in the following three notable group types:

1. computer groups-groups that gather at one of the many library-owned computers in the commons

2. table groups-groups studying in the commons without the use of the library computers (note that this count includes groups using their own laptops)

3. study room groups-groups using the two collaborative learning rooms (technology enhanced group study rooms)—although statistics were kept about these groups, the results were deemed not to be useful because there were only two rooms and the rooms were consistently used throughout the semester

For purposes of this study, a standard was set to define a group. A group was defined as "two or more people talking together in the Commons". One caution when using this simplistic definition is that we do not know the nature of the conversations taking place in the groups, whether academic or social. We did not pry into the nature of the conversations, but merely observed if it took place. Regardless of the nature of the dialog, the fact that the conversations take place in the library, rather than other places on campus, is a good reflection of the success of the commons.

The group count was done every hour on the half-hour and recorded in a simple Microsoft Excel spreadsheet. At BYU most of the scheduled classes begin on the hour and end fifty minutes later. The count on the half hour gave enough time for those beginning group work to settle in and those finishing group work to leave the library. Over time, this has given a good average of the number of groups studying in the 
commons for any given hour. Counting at such regular and frequent intervals provided adequate data for evaluation and analysis. It also provided flexibility to consider a variety of circumstances (e.g., breaks between semesters or holiday days when the library is open, etc.).

The data collection started in June 2005 and continues to the time of writing. At first, data gathering consistency was an issue due to the changes in the normal workflow of those recording the statistics. To address this issue, one of the students was asked to find and implement a computer clock that included the ability to set reminders and sound alarms every hour on the half-hour. The program nth Clock (http://www.anthemion.org) was selected and installed on the two information commons assistants' computers. Consistency did improve with this implementation and as the data collection became a normal part of the work flow.

For this paper we decided to use averages instead of reporting group totals. One reason for this was that despite having the alarm and having it a normal part of the work flow, some group counts were still missed. The other reason was that use of the commons varied by day, time of day and by time of the semester. We wanted to be able to show how well the commons was used on an average day during an average semester. Every month the three group types were averaged individually for each time statistics were kept, and then those monthly averages were averaged together to give us a semester average. This gave us a good idea of the group use of the commons for each semester during the times the library was open. 


\section{Considerations of the Information Commons Environment}

Throughout the time of the data gathering process, changes occurred in the physical makeup of the commons, i.e. the number and layout of computers. In addition, there were other possible influences on the results: individuals using the space for study, groups using their own laptops, and variations in what data gatherers considered a "group." While examining the results, these considerations need to be remembered. Each one is discussed below.

1. In the short time it has been in operation, the commons has become a popular place to study in the library. As a result, additional computers were added to the commons twice after its initial implementation. These two additions of computers have resulted in the optimal number of computers in the commons. Lines of students, while seen often in the past, now occur rarely and only during times of the day or semester that are most busy (e.g., reading days and finals). Some of the increase in groups studying at computers reported in this paper can likely be explained in part by this increase in the number of computers in the commons. Future measurements will reflect a more accurate view of the trends in groups studying, without the influence of added computers.

2. Not only is the information commons used for group work, but also many students use the space for individual study as well. Individual study may occur in the commons because of the large number of computers and that the location is so close to the main entrance of the library, increasing the likelihood of using the commons instead of venturing into other more remote parts of the library. These individual stations are occasionally used for groups. More often, however, 
potential group study space, both with a computer workstation and without, is occupied by individuals. This report does not attempt to address this issue of individuals using potential group study space.

3. Students in the commons often use their own laptops for studying in groups or as individuals. However, the statistics did not indicate if the students were studying in groups using their own laptops. These groups were counted as groups at a study table (i.e. not using a library-owned computer). This was deemed acceptable because this study deals with the number of groups using the space and equipment provided by the library.

4. Lastly, those who record the statistics may assign group status differently from one another. Each person is trained on the standard mentioned above (a group is two or more people talking together), but the obviousness of the conversation might be interpreted differently from one person to another. This is not very worrisome due to the volume of data that is collected and that we are using averages, but it should be considered when evaluating the data.

\section{Results}

The results will be examined in two sets. The first set of data is the general use of the commons, that is, the average use by groups by hour throughout the entire semester, not including reading days and finals. This set also includes a comparison of group use between fall and winter semesters. The other is the set of data dealing with the use of the commons during reading days and finals, when classes were not in session. This division was made because the number of people using the commons is significantly greater during reading days and finals (see Figure 6) with the potential of skewing the 
data for the entire semester. The analysis of each of these sets was done in two ways: first, a reporting of the hourly averages to discover how heavily the commons is used throughout the day; and second, a comparison between semesters to see if group use of the commons increased or decreased from one semester to the next. After examining the results of these two sets separately, the results of each group will then be compared.

\section{Set 1: Group Averages without Reading Days and Finals}

Measuring the total number of groups studying in the commons was the initial intent for the group count. For purposes of this evaluation, individuals using the commons were not counted because our focus was entirely on groups in the commons. However, anecdotal evidence from those working on the information desk indicates that most of the time the majority of the commons computers are being used by individuals. When we look at the total number of computers available in the commons (121) and compare those to the gathered group statistics this is reinforced. This is partially attributable to the fact that many (63) of the computers are designed for individual use. However, if we consider that there are only fifty-eight computers that are designed for group use, we realize that, at times, those computers meant for groups are being used heavily by groups. It should also be noted that between 9:30 a.m. and 6:30 p.m. there is rarely a computer available in the commons for either group or individual use; occasionally, there is a line of students waiting to use a computer, even though there are unused computers available elsewhere in the library. The students are willing to wait the five to ten minutes for a computer in the commons rather than go to another area of the library to use a computer sooner. In addition, few of the study spaces without computers (i.e. 
tables, chairs or floor space) are available during the same time period. In other words, the commons reaches the saturation point sometime around 9:30 a.m. and it lasts until about 6:30 p.m.

Table 1 shows the average number of groups studying during the times we gathered statistics ( $\mathrm{C}=$ group at a library computer, $\mathrm{T}=$ group at a study table, Tot.=total number of groups). The time of day with the most groups studying in the information commons is between 10:30 a.m. and 4:30 p.m. After 4:30 p.m. the number of groups remains somewhat steady until it drops between 10:30 p.m. and 11:30 p.m., which is shown in Figure 1.

\begin{tabular}{|c|c|c|c|c|c|c|c|c|c|c|c|c|}
\hline \multirow[b]{2}{*}{ Time } & \multicolumn{3}{|c|}{$\begin{array}{l}\text { Fall } 2005 \\
\text { Averages }\end{array}$} & \multicolumn{3}{|c|}{$\begin{array}{c}\text { Winter } 2006 \\
\text { Averages }\end{array}$} & \multicolumn{3}{|c|}{$\begin{array}{l}\text { Fall } 2006 \\
\text { Averages }\end{array}$} & \multicolumn{3}{|c|}{$\begin{array}{c}\text { Winter } 2007 \\
\text { Averages }\end{array}$} \\
\hline & C & $\mathbf{T}$ & Tot & C & $\mathbf{T}$ & Tot & C & $\mathbf{T}$ & Tot & C & $\mathbf{T}$ & Tot \\
\hline 7:30 AM & 0 & 0 & 1 & 0 & 0 & 0 & 1 & 0 & 1 & 0 & 0 & 0 \\
\hline $8: 30 \mathrm{AM}$ & 2 & 2 & 4 & 2 & 2 & 4 & 3 & 3 & 6 & 2 & 2 & 4 \\
\hline $9: 30$ AM & 4 & 6 & 10 & 5 & 4 & 9 & 5 & 6 & 11 & 4 & 4 & 8 \\
\hline 10:30 AM & 6 & 10 & 16 & 7 & 7 & 14 & 8 & 8 & 16 & 7 & 8 & 15 \\
\hline $11: 30$ AM & 7 & 11 & 18 & 8 & 11 & 19 & 9 & 10 & 19 & 8 & 9 & 17 \\
\hline 12:30 PM & 7 & 11 & 18 & 8 & 8 & 16 & 9 & 8 & 17 & 9 & 9 & 18 \\
\hline 1:30 PM & 7 & 10 & 17 & 8 & 8 & 16 & 9 & 8 & 17 & 9 & 10 & 19 \\
\hline 2:30 PM & 6 & 10 & 16 & 8 & 9 & 17 & 10 & 10 & 20 & 9 & 10 & 19 \\
\hline 3:30 PM & 9 & 13 & 21 & 9 & 10 & 19 & 11 & 11 & 22 & 10 & 11 & 21 \\
\hline 4:30 PM & 7 & 11 & 18 & 8 & 10 & 18 & 10 & 10 & 20 & 9 & 11 & 20 \\
\hline 5:30 PM & 7 & 9 & 16 & 7 & 7 & 14 & 9 & 9 & 18 & 8 & 9 & 17 \\
\hline 6:30 PM & 6 & 8 & 14 & 7 & 6 & 13 & 7 & 7 & 15 & 7 & 7 & 14 \\
\hline 7:30 PM & 5 & 7 & 12 & 6 & 5 & 11 & 7 & 7 & 14 & 7 & 6 & 13 \\
\hline 8:30 PM & 6 & 8 & 14 & 7 & 6 & 13 & 8 & 8 & 16 & 6 & 6 & 12 \\
\hline 9:30 PM & 7 & 8 & 15 & 7 & 7 & 14 & 9 & 8 & 17 & 7 & 7 & 14 \\
\hline 10:30 PM & 5 & 6 & 12 & 5 & 5 & 10 & 6 & 6 & 12 & 5 & 5 & 10 \\
\hline 11:30 PM & 3 & 4 & 7 & 3 & 3 & 6 & 4 & 3 & 7 & 3 & 3 & 6 \\
\hline
\end{tabular}

Table 1: Averages of groups by semester (without reading days \& finals)

In addition to showing the increase at the beginning of the day and the decrease at the end of the day, Figure 1 shows how the averages compare by semester throughout the 
times that statistics were gathered. It is easy to see from this graph that after 3:30 the fall semesters have more groups, although not significantly, than winter the semesters. Before 3:30 there is no consistency of which semester has more groups using the commons.

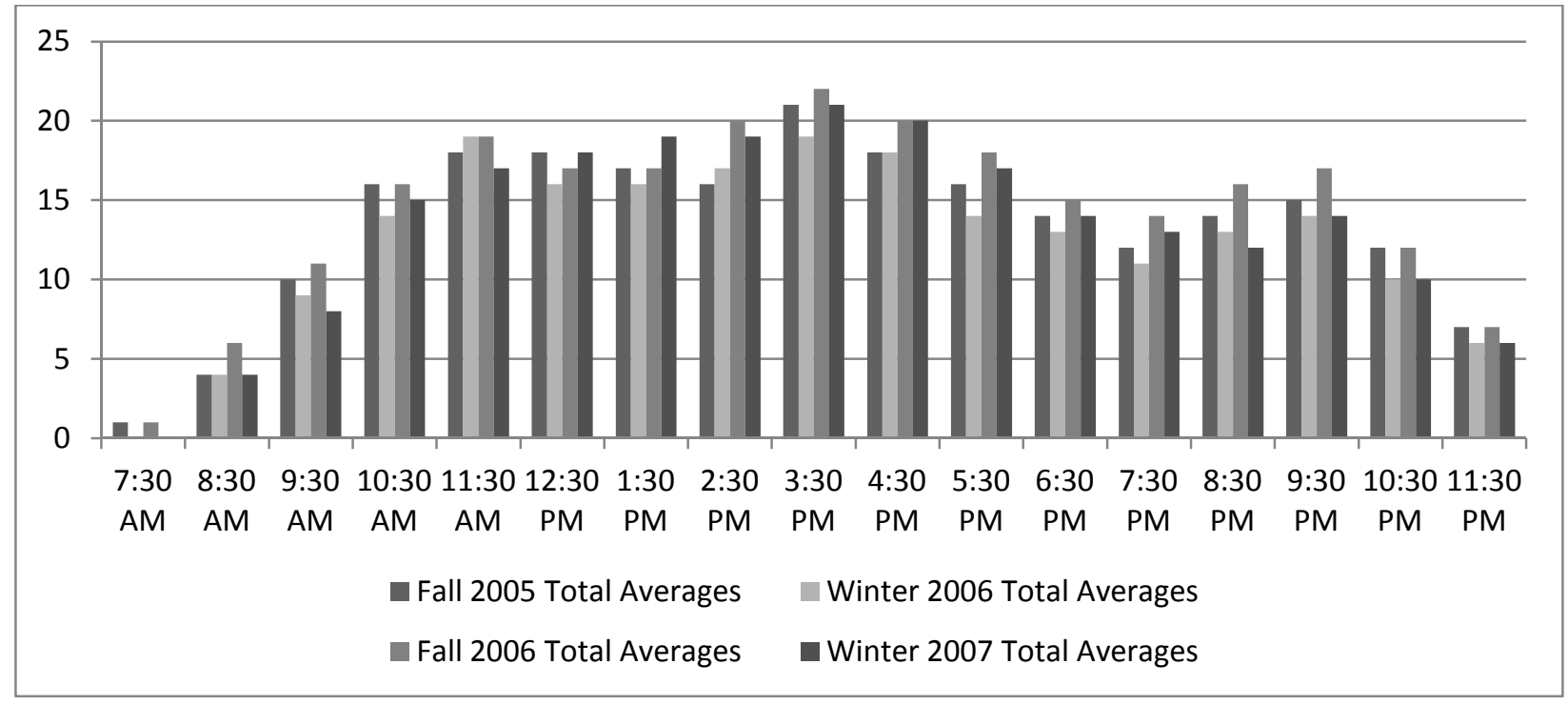

Figure 1: Semester total averages comparison by time of day

Figure 2 shows that the number of groups studying in the commons is consistent across the four semesters, and that there are similar peaks and valleys. This, then, appears to contradict an initial hypothesis that fall semester group study habits differ from winter semester. The reason for the initial hypothesis of a difference between semester types (i.e. between fall and winter) is the nature of the university and the change in enrolments between fall and winter (usually fewer enrolments during winter than during fall). Another possible reason for this consistency is that the commons often reaches the saturation point during much of the day when most available seats are occupied. 


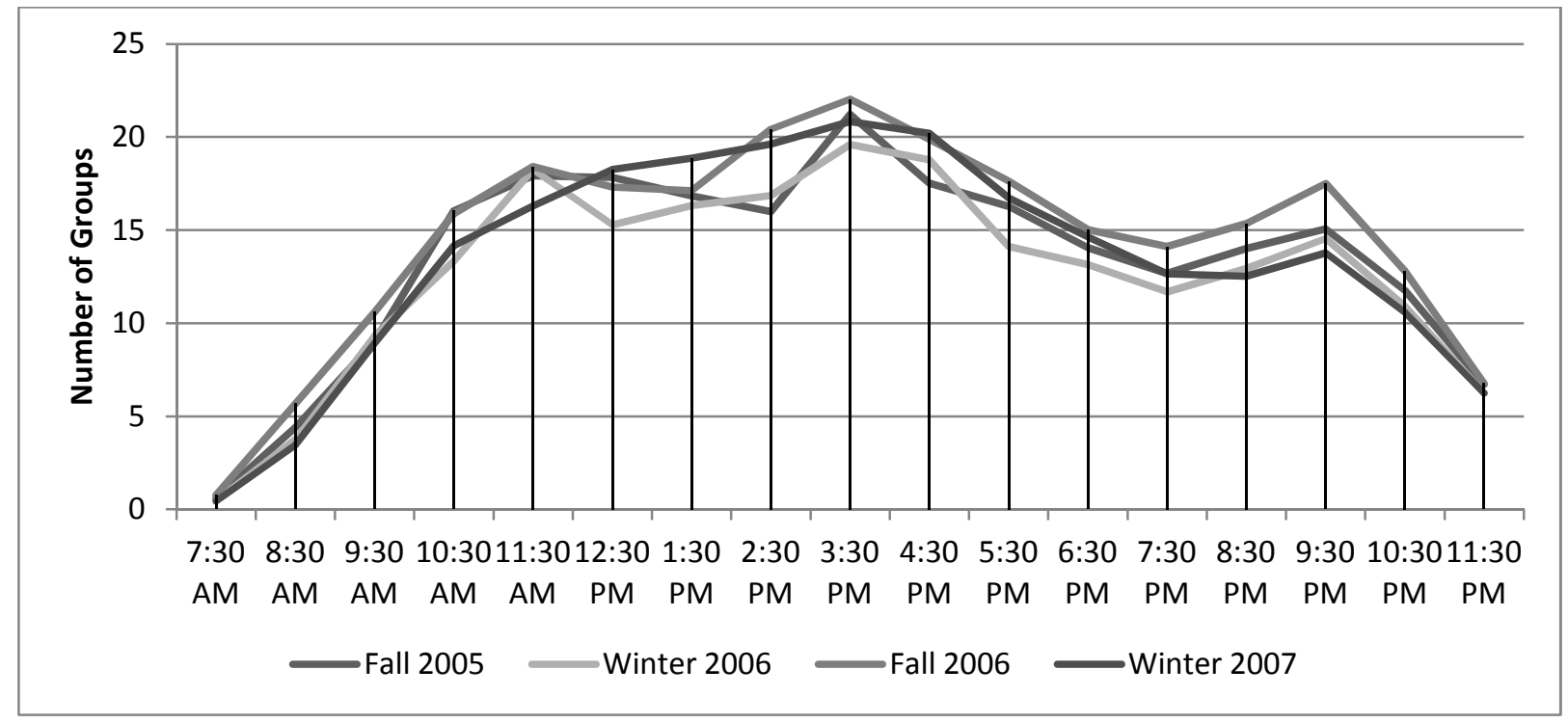

Figure 2: Averages Not Including Reading Days and Finals

Figure 2 also shows that between the hours of 10:30 a.m. and 6:30 p.m. there are on average between fifteen and twenty groups studying in the commons. This constitutes the majority of time that the library, and thus the Commons, is open. Between 8:30 p.m. and 9:30 p.m. there is another rise in the number of groups. It is assumed that the dip occurs during dinner/break time, though a more in depth study would need to be done to confirm this. The difference between semester types, though negligible, is more apparent after 7:30 p.m. when there are slightly more groups in the commons during fall semesters than during winter semesters. In addition, the number of groups for every semester peaks at 3:30 p.m. A possible explanation for this is that BYU offers the majority of classes during the morning and early afternoon hours of the day. The data imply that many people are using the time right after classes to gather with their groups.

\section{Trends in Group Studying—Differences between years}

In order to understand if group use of the information commons has changed over time, a comparison was made between the first and most recent semesters that statistics 
were taken. Figure 3 shows the results of this comparison. Shown is the difference (most recent year minus the previous) in the averages during the time the library is open. This type of comparison will continue to be useful in the future as changes are made to the commons. We will be able to determine if the changes had a positive or negative effect on the group use of the commons.

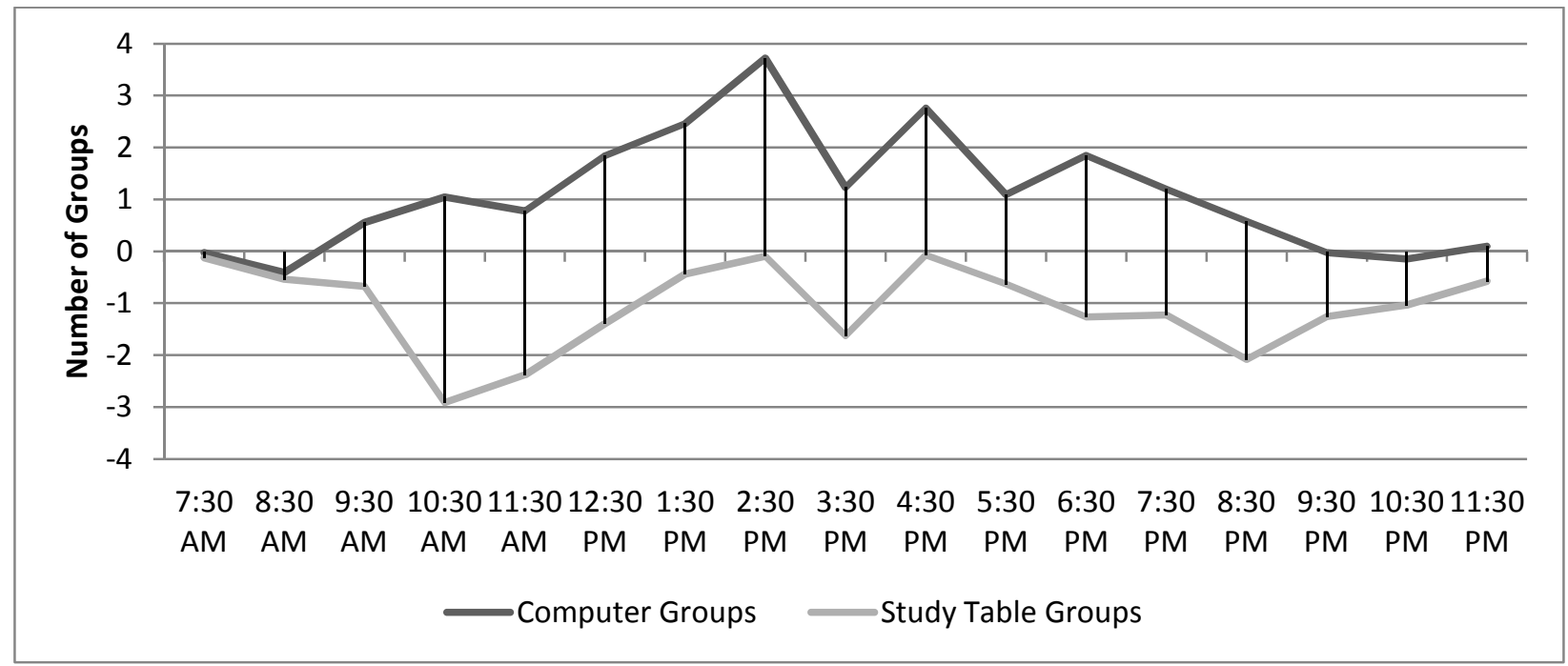

Figure 3: Winter 2007 and Fall 2005 Difference

In this particular case we can see that computer group use of the commons has increased over time while table groups have decreased. This can likely be attributed to the increase in the number of computers for group use while at the same time reducing usable space for table groups. As the number of group computers available in the commons remains steady, this comparison will become more useful.

\section{Set 2: Reading Days and Finals}

The information commons is used to a much greater extent during reading days and finals. From anecdotal observations made by those who count groups, the use of the commons is steadier and greater during those days and the commons is home to more groups who use the space for a longer period of time. 
Table 2 and Figure 4 show the average use of the commons during reading days and finals. These numbers are significantly higher than those gathered during the normal part of the semester. This is expected, since classes are not held during reading days and finals. The difference between the normal days and reading days and finals is discussed in the next section of this paper and is shown in Figure 6.

\begin{tabular}{|c|c|c|c|c|c|c|c|c|c|c|c|c|}
\hline \multirow[b]{2}{*}{ Time } & \multicolumn{3}{|c|}{$\begin{array}{l}\text { Fall } 2005 \\
\text { Finals } \\
\text { Averages } \\
\end{array}$} & \multicolumn{3}{|c|}{$\begin{array}{c}\text { Winter } 2006 \\
\text { Finals } \\
\text { Averages } \\
\end{array}$} & \multicolumn{3}{|c|}{$\begin{array}{c}\text { Fall } 2006 \\
\text { Finals } \\
\text { Averages }\end{array}$} & \multicolumn{3}{|c|}{$\begin{array}{c}\text { Winter } 2007 \\
\text { Finals } \\
\text { Averages } \\
\end{array}$} \\
\hline & C & $T$ & Tot & C & $\mathbf{T}$ & Tot & C & $\mathbf{T}$ & Tot & C & $T$ & Tot \\
\hline 7:30 AM & 0 & 0 & 0 & 1 & 1 & 2 & 0 & 1 & 1 & 0 & 1 & 1 \\
\hline 8:30 AM & 2 & 3 & 5 & 3 & 6 & 9 & 5 & 8 & 13 & 3 & 3 & 5 \\
\hline 9:30 AM & 7 & 12 & 18 & 10 & 14 & 25 & 10 & 14 & 24 & 10 & 15 & 25 \\
\hline 10:30 AM & 8 & 14 & 22 & 13 & 21 & 34 & 16 & 18 & 34 & 15 & 20 & 34 \\
\hline $11: 30 \mathrm{AM}$ & 9 & 19 & 28 & 12 & 19 & 31 & 10 & 17 & 27 & 14 & 17 & 31 \\
\hline 12:30 PM & 7 & 18 & 24 & 11 & 16 & 27 & 10 & 17 & 27 & 13 & 16 & 29 \\
\hline 1:30 PM & 8 & 20 & 28 & 12 & 16 & 28 & 11 & 17 & 27 & 15 & 19 & 33 \\
\hline 2:30 PM & 9 & 22 & 31 & 9 & 13 & 22 & 13 & 20 & 32 & 13 & 18 & 31 \\
\hline 3:30 PM & 9 & 18 & 27 & 10 & 14 & 24 & 9 & 14 & 23 & 16 & 17 & 33 \\
\hline 4:30 PM & 8 & 17 & 25 & 9 & 18 & 27 & 7 & 14 & 21 & 11 & 16 & 27 \\
\hline 5:30 PM & 7 & 15 & 22 & 8 & 14 & 23 & 8 & 13 & 21 & 12 & 13 & 26 \\
\hline 6:30 PM & 4 & 12 & 16 & 7 & 13 & 19 & 9 & 13 & 22 & 10 & 12 & 22 \\
\hline 7:30 PM & 5 & 11 & 16 & 5 & 11 & 16 & 10 & 12 & 22 & 8 & 11 & 18 \\
\hline 8:30 PM & 7 & 19 & 25 & 6 & 12 & 18 & 8 & 12 & 20 & 7 & 11 & 18 \\
\hline 9:30 PM & 8 & 17 & 25 & 7 & 12 & 19 & 8 & 12 & 20 & 9 & 13 & 22 \\
\hline 10:30 PM & 9 & 17 & 25 & 9 & 12 & 22 & 6 & 8 & 14 & 7 & 10 & 17 \\
\hline 11:30 PM & 6 & 12 & 18 & 6 & 8 & 14 & 4 & 9 & 13 & 7 & 8 & 15 \\
\hline
\end{tabular}

Table 2: Averages of groups by semester for reading days \& finals

Similar to the normal days of the semester, Figure 4 shows that each semester's use of the commons during reading days and finals has similar peaks and valleys, though different from those during the normal semester. It is interesting to note that during fall 2005 , between $8: 30$ p.m. and 11:30 p.m., the number of groups using the commons is much larger than the other semesters; however, we do not know why this is so. 


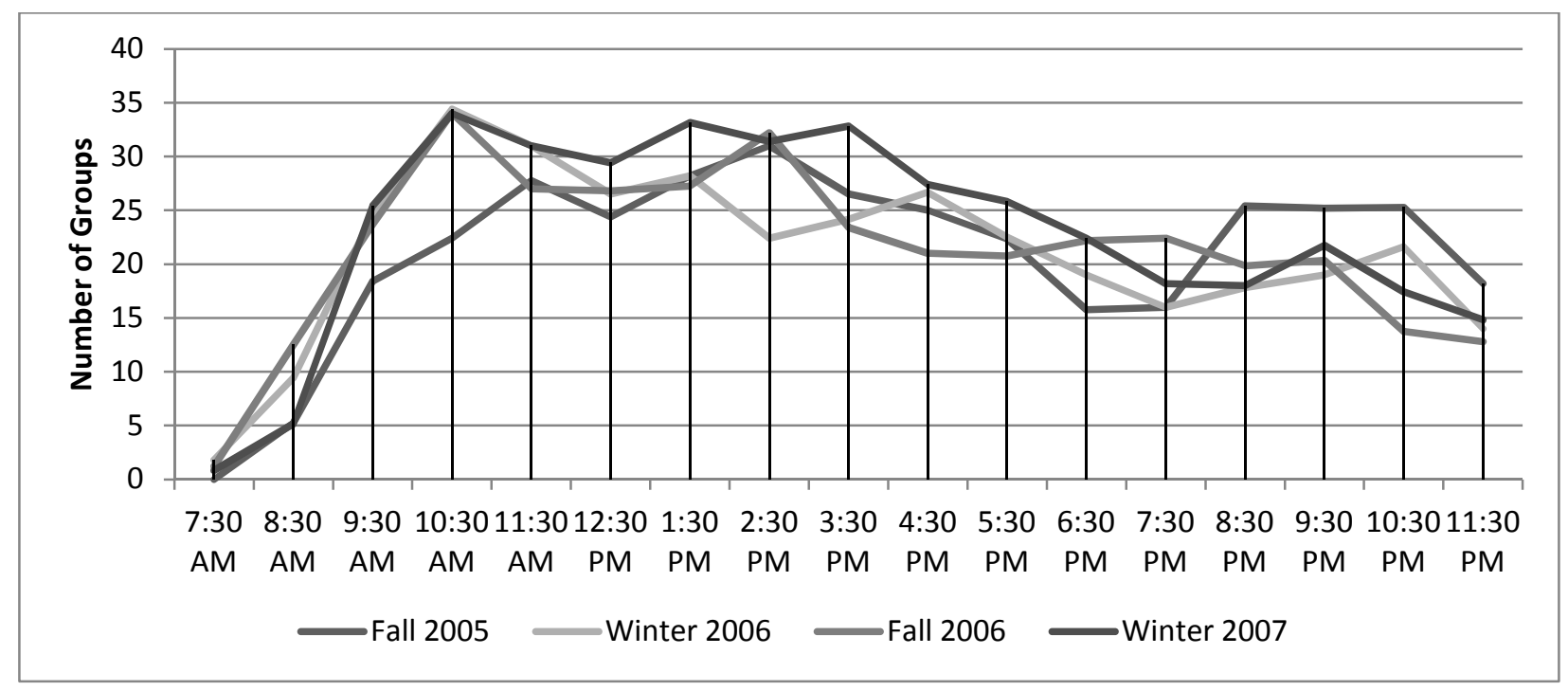

Figure 4: Reading Days and Finals Averages

\section{Trends in Group Studying-Differences between semesters}

Unlike what we saw during the regular semester in general, used the commons more in each succeeding semester, shown in Figure 5. Expectations are that future comparisons will show that the average number of groups using the Commons will level off. We believe that the past increases can be attributed to the addition of computers noted in the Environment section of this report. In addition, the saturation point in the information commons will be reached more often as more students discover the commons. 


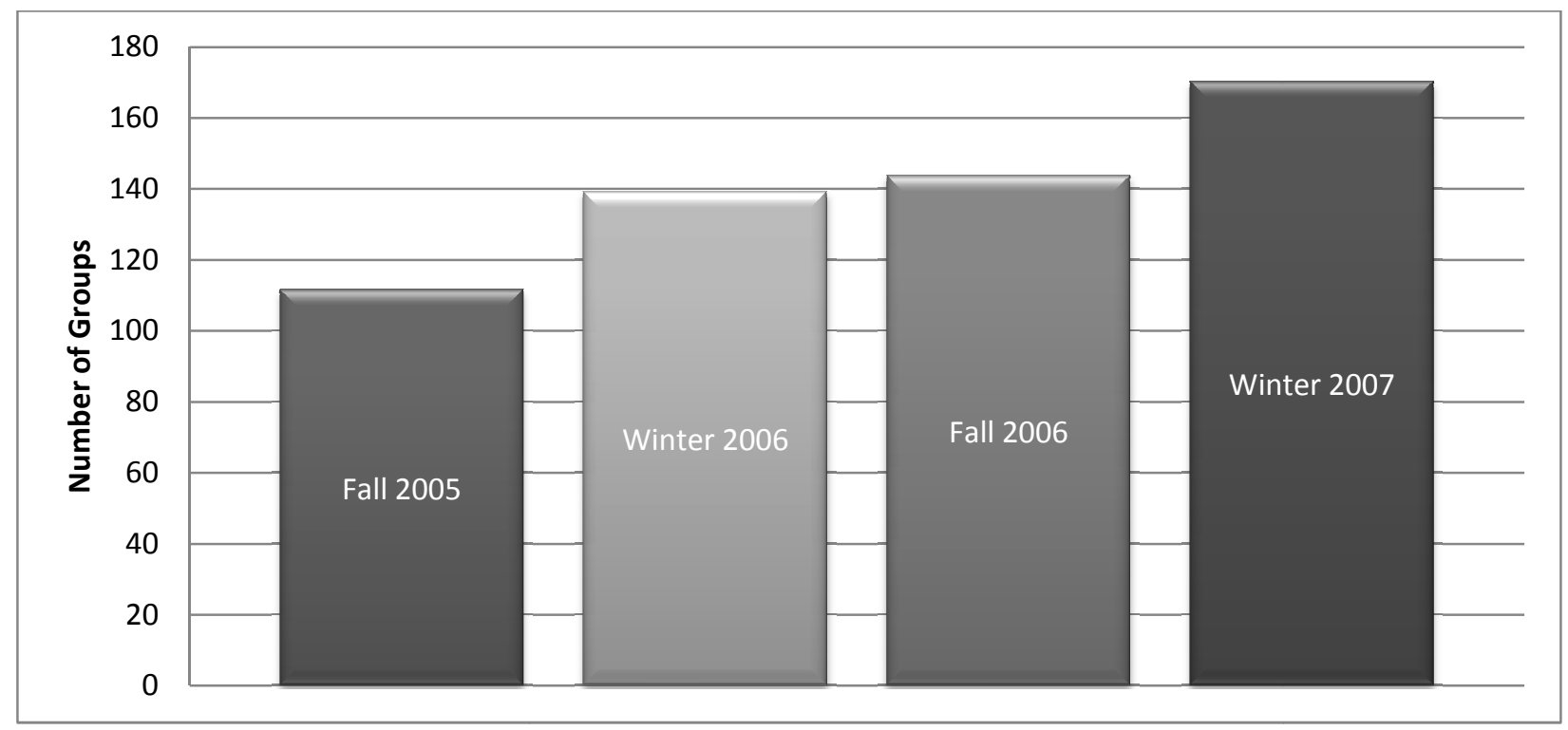

Figure 5: Reading Days \& Finals: Total Average Number of Groups

\section{Comparing Finals to Regular semester}

The comparison between regular semester days and reading days and finals provides

an insight into how students use the commons during those two time periods. The data showing use during both the regular semester and the finals period demonstrate that the commons is being used by groups. This use of the commons reinforces one of the primary functions of the information commons, which is to provide a space for group work in the library. 


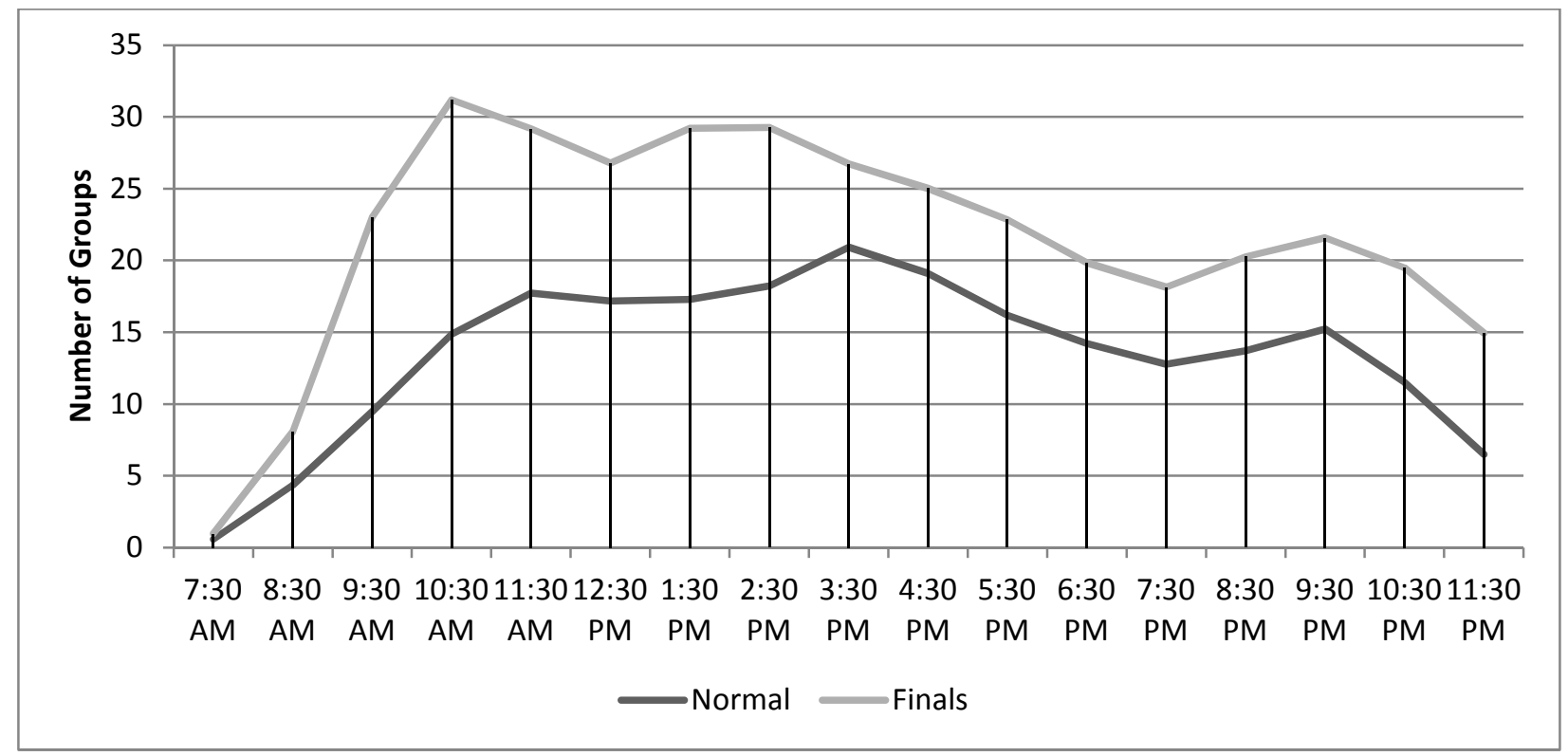

Figure 6: Finals and Normal Comparison (2005-2007 cumulative averages)

Figure 6 shows the 2005-2007 cumulative averages of both normal days and reading days and finals. The averages during reading days and finals for the first part of the day until 3:30 are between ten and fifteen groups higher than during the normal semester. The most notable observation about the comparison in Figure 6 is that between 8:30 a.m. and 10:30 a.m. reading days and finals averages are about twice that of the averages during the normal semester. After 2:30 the difference is consistently five to seven groups more during reading days and finals. However, the trend lines after 3:30 p.m. are the same (i.e. gradual decrease from 3:30 p.m. to 7:30 p.m. at which point they rise again and then decrease after 9:30 p.m.). Figure 6 also shows that the commons is most busy during reading days and finals at 10:30 a.m., whereas the peak comes at 3:30 p.m. during normal days.

\section{Conclusion and Looking to the Future}

The data gathered during this study show that the commons is being used by those for whom it was partially intended: groups wanting a space to study in the library. When 
the commons was built it was intended to provide and is being used as space for groups but it is extensively used by individuals as well. Design features in the commons that have encouraged and increased its use for this purpose include making the space a "No Shhh! Zone," continually adding more collaborative workstations, providing support for not only research but computers as well, and having the location of the commons near the entrance to the library. In the future, we will have a greater longitudinal comparison with which we can gauge the effects of implemented changes on the number of groups studying in the commons. This will help us improve services that support group studying at BYU. The data gathered for this study will serve as a baseline for future work.

We do not know what the future holds for this information commons, nor for the concept as a whole. However, as this commons remains flexible as times change, it will continue to adapt to those changes in technology and to the curriculum and study needs of those using the Harold B. Lee Library on the campus of Brigham Young University. 


\section{References}

Whitchurch, M. J., C. J. Belliston, and W. Baer. 2006. Information commons at Brigham Young University: Past, present, and future. Reference Services Review 34:261. 